Cristián Johansson F.

Profesor de la Facultad de Teología

Pontificia Universidad Católica de Chile

\title{
Revista Teología y Vida, vol. XLIV año 2003, N² 2-3
}

Presentar el número doble de la revista Teología y Vida del año 2003, dedicado al tema de la religiosidad popular, obliga a realizar una mirada retrospectiva, pues la preocupación de la Facultad, por reflexionar la piedad popular, tiene larga data. Ese año 2003 se cumplían 30 años del primer Encuentro sobre religiosidad popular que tuvo lugar en Santiago en diciembre de 1973. Cuatro años más tarde, en mayo de 1977, se organizaba un nuevo Encuentro con el Equipo Pastoral de Maipú. Ambos contaron con invitados extranjeros, duraron una semana y dieron origen a sendos libros.

Casi una década después, en 1986, la Facultad organiza el primer Seminario interdisciplinario sobre Evangelización, Cultura y Religiosidad Popular, cuyas conclusiones están en el número doble de Teología y Vida del año siguiente. Pasaron más de tres lustros, pero el interés por la religiosidad popular había permanecido.

En el año 2002 se presenta una nueva oportunidad de retomar el tema con ocasión del Tercer Congreso Americano de Rectores de Santuarios, que le correspondió a la Iglesia chilena organizar en la localidad de Padre Hurtado, en noviembre de ese año. La Facultad no quiso estar ajena a ese acontecimiento y decide llevar a cabo un segundo Seminario cuyo tema fue: Religiosidad popular y espacio sagrado. Este Seminario -al igual que los anteriores- tuvo características interdisciplinares y presencia de invitados extranjeros. El número de Teología y Vida que se presentará a continuación es el fruto de dicho Seminario.

Buscando un hilo conductor de las ideas expresadas en los artículos de este número, se ha elegido como punto de partida el del Prof. Luis Flores, que refiere a la fenomenología de la espacialidad en el horizonte de la corporalidad. El texto se inicia con el análisis de la distinción cartesiana entre el alma como sustancia pensante y el cuerpo como sustancia extensa. Esta distinción tiene consecuencias para la comprensión del propio cuerpo y el cuerpo de los otros. También la diferenciación newtoniana entre espacio absoluto y espacio relativo tiene como trasfondo el concepto de res extensa.

Con Husserl acontece un cambio de perspectiva. Se distingue, entre cuerpo vivido (Leib) y cuerpo mecánico (Körper), el cual pertenece al ámbito de las cosas extensas. El espacio se considera, ahora, inscrito en el horizonte de la percepción y la corporalidad. 
Heidegger, por su parte, plantea que la espacialidad es esencial al Dasein, la cual no significa encontrarse en algún lugar del espacio cósmico, sino tener las características de des-alejación (Entfernung) y direccionalidad (Ausrichtung), las cuales no coinciden con el espacio métrico pues son existenciales.

Merleau-Ponty aporta nuevos elementos al sostener que el cuerpo es un nudo de significaciones en el contexto de un determinado mundo. El cuerpo propiamente no está en el espacio ni en el tiempo, sino que los habita.

El espacio natural se encuentra traspasado por el espacio antropológico. Un lugar significativo del espacio antropológico es el espacio mítico, porque conforma un mundo con elementos interrelacionados, poseedores de sentido para el individuo.

Desde la fenomenología de la religión, según lo explica Van der Leew, el espacio sagrado posee características peculiares al constituirse en el lugar donde se repite el efecto del poder y se realizan acciones cultuales humanas.

Estas referencias al pensamiento fenomenológico permiten mostrar la evolución de la comprensión del espacio. Inicialmente concebido como espacio geométrico, homogéneo e isotrópico, para posteriormente abrir paso a una concepción del espacio como una realidad vivida, que es esencialmente heterogénea, anisotrópica, dinámica, plena de relieves, pregnancias y dimensiones afectivas. Surge, así, el concepto de espacio vivido.

La tesis del Prof. Flores es que el espacio sagrado es una modalidad del espacio vivido donde se articulan, en torno a lo sagrado, las cuatro intencionalidades básicas que comporta dicho espacio. Estas son: la cognitiva, la deóntica o pragmática, la sintomática, es decir, la que es vestigio del ser humano y su cultura, y la estética. Se destacan para el espacio sagrado las tres últimas por sobre la cognitiva.

Lo planteado por el Prof. Flores adquiere concreción en la presentación del Prof. Antonio Bentué, donde se caracteriza el espacio sagrado en algunas religiones no cristianas, tales como el hinduismo, budismo, islamismo y la religión mapuche.

Desde el punto de vista de la fenomenología de la religión, el espacio sagrado se deriva de la realidad sólida que surge de una situación, a la vez hierofánica y kratofánica, que posibilita la relación a lo sagrado, por medio de una experiencia teofánica. Las celebraciones mítico-rituales que acontecen en estos espacios expresan la autoconciencia de la existencia no fundada.

Como consecuencia de esta experiencia se postula un espacio sagrado situado en un tiempo mítico, donde el cielo y la tierra se encuentran conectados. El creyente, al actualizar y apropiarse de ese espacio, accede a la salvación. En el caso del hinduismo existe un espacio sagrado mítico donde se unen el ser supremo y los seres que habitan el espacio profano, propio de la multiplicidad. Es la montaña en forma de cono llamada Suméru, ubicada en el centro de la superficie terrestre, en el eje vertical del cosmos. En la cima está Amaravati -la ciudad inmortal-, morada de los dioses eternos y de los que han alcanzado la inmortalidad al haber superado el ciclo de las reencarnaciones.

Esta concepción del espacio sagrado se prolonga en el budismo y se conserva en los santuarios budistas con las edificaciones llamadas Stupas, que mantienen la misma estructura simbólica. En el islam destacan como lugares sagrados las mezquitas. La primera -a la que se peregrina anualmente- está ubicada en la ciudad santa de La Meca, donde se encuentra la Kaaba, cuyo muro sostiene la piedra sagrada de 
basalto negro. También las mezquitas El Aksa y Omar situadas en Jerusalén son de gran importancia. En el interior de toda mezquita está la Mihrab, que es el lugar que marca la dirección hacia La Meca y determina la orientación de los orantes.

Tanto en las religiones indianas como en el islam se da paralelamente un proceso de interiorización del espacio sagrado hacia la intimidad del creyente, particularmente en la espiritualidad "mística". El espacio sagrado queda, así, relativizado. Para el monje budista el espacio sagrado es la soledad. En el islam, los místicos sufíes relativizan el espacio sagrado externo, colocando el corazón humano como el santuario más apropiado para adorar a Alá, orientado solo en la dirección del amor.

En la religión mapuche, se analizan el Ngillatuhue y el Rehue como espacios sagrados. El Ngillatuhue es el lugar donde se celebra, cada cuatro años, el Ngillathun o Rehuen (consagración de la Tierra), que tiene como centro sacral el Llangi, un tronco esculpido que presenta, en la parte superior, un rostro tallado (Rehue) cubierto por ramas de canelo.

El artículo del Prof. Bentué hace ver los muchos elementos comunes que tienen estas cuatro religiones con relación al espacio sagrado que, con lo expuesto por la Prof. Christine Fitzurka, se amplía hacia el espacio sagrado en el cristianismo al presentar los planteamientos de la teología oriental en torno al icono.

La autora, al iniciar su reflexión, considera que en la ortodoxia no existe la religiosidad popular en los mismos términos que en el catolicismo. Ello se debería al modo como se concibe teológicamente el icono, cuya comprensión se hace extensiva a la realidad cósmica, a la materia y a lo espiritual; como dimensiones de lo creado, que son portadoras de gracia transfiguradora. La Resurrección del Verbo de Dios encarnado ha transfigurado, redimido y glorificado la creación de Dios. Así, lo sagrado penetra lo cotidiano. Dios se ha hecho hombre para que el hombre se divinice.

La Encarnación y la Transfiguración son dos acontecimientos en estrecha relación con el icono. El primero fundamenta la legitimidad de plasmar a Dios en una imagen. El segundo impide hacer una representación física (un retrato) en lo pintado. El icono tiene un lugar importante en el mundo cotidiano. Además de tener iconos en los diferentes espacios de la casa, el cristiano ortodoxo siempre tiene en su hogar un lugar especial donde se ora frente a los iconos de la familia. La condición del icono como espacio sagrado hace de la labor del iconógrafo un ministerio que está unido, de modo directo, a la vida de la Iglesia. Para ejercerlo se necesita una preparación tanto artística como espiritual. El icono pertenece al arte de la Iglesia, pero es inseparable del plan santificante, transformante y sanante del hombre y el cosmos.

Una vez completada la presentación del icono como espacio sagrado, un nuevo paso en el desarrollo de la temática se encuentra en los planteamientos sobre el espacio sagrado y la Iglesia. Un tema que es abordado desde tres perspectivas: dos de ellas teológicas y una histórico-política.

El artículo del Prof. Rodrigo Polanco reflexiona sobre la Iglesia como espacio sagrado a partir de la afirmación de Lumen Gentium, que considera a la Iglesia "como sacramento o signo e instrumento de la unión íntima con Dios y de la unidad de todo el género humano". En consecuencia, ella constituye un lugar de encuentro de los hombres con Dios y de los hombres entre sí. Esto es posible porque la 
Encarnación es la entrada definitiva de Dios al espacio humano. La Iglesia prolonga esa presencia, de un modo sacramental, pues es el Cuerpo de Cristo y Templo de su Espíritu. La presencia del Verbo se realiza en la Iglesia y se hace accesible en las personas y en la institución, pues la Iglesia es Pueblo de Dios. Su constitución fundamental es la de ser un acontecimiento institucional de encuentro. Como espacio social de la fe, la Iglesia es mucho más que la simple reunión de creyentes. Ella transmite la fe y la articula de modo personal y comunitario.

Jesucristo, como el absoluto que ha devenido en concretísimo, es el Salvador absoluto. Ha transformado la humanidad haciéndola sagrada. Por su vínculo a Cristo, la humanidad se constituye en espacio de salvación. Lo que se le hace a los pequeños hermanos de Jesús se le hace a Él. La salvación es, entonces, inseparable de este principio encarnatorio y se ofrece en un signo finito y pecador como es la Iglesia. Ella concreta y media de modo categorial la salvación gratuita ofrecida en Cristo. Es el acontecimiento salvífico permanente, es decir, espacio sagrado de salvación.

Jesucristo no suprime los espacios sagrados, sino que los transforma y les da una nueva consistencia, pues los dota de una realidad ontológica nueva, a partir de su propia corporalidad. El espacio sagrado eclesial de encuentro, que es el pueblo de Dios, tiene una marcada índole escatológica, pues es concreción del acontecimiento pascual. En él se hace presente la restauración prometida, que ya ha tenido lugar en Cristo. El final de la historia ya ha acontecido de modo irrevocable y la Iglesia peregrina lo anticipa, en sus instituciones y sacramentos.

La Eucaristía es el sacramento que está estrechamente vinculado a la dimensión escatológica anticipatoria del encuentro definitivo en el banquete del Reino. Por medio del Espíritu la Iglesia transmite infaliblemente los bienes del Reino a través de la Palabra y los Sacramentos. Es, en este sentido, también un espacio escatológico de encuentro, que hace ver que lo importante no es el espacio sagrado mismo, sino el don recibido que es Cristo, a quien se acoge por obra del Espíritu.

Las formas institucionales son, entonces, instrumento de gracia, pues el Resucitado y el Espíritu las han validado como concreciones de la presencia y las acciones de Cristo mismo. La dimensión escatológica del espacio eclesial remite la realidad institucional de la Iglesia más allá de sí misma, es decir, al misterio absoluto, el Dios que es uno en tres Personas.

Lo expuesto por el Prof. Polanco sirve como horizonte donde se puede integrar una manifestación eclesial concreta, que tiene características de espacio de encuentro. Se trata del análisis que el Prof. Carlos Galli hace de las peregrinaciones. Elige, como concepto inspirador, las palabras de Juan Pablo II en Novo millennio ineunte, donde el Papa relata lo que pensaba al mirar las largas filas de peregrinos, que esperaban pacientemente transitar a través de la Puerta Santa. Entre sus reflexiones está la siguiente: "Observando también el continuo fluir de los grupos los veía como una imagen plástica de la Iglesia peregrina". Esta expresión fundamenta la propuesta del Prof. Galli en relación a la comprensión de las peregrinaciones: la peregrinación es la imagen plástica del pueblo de Dios peregrino.

Partiendo de las peregrinaciones recientes, con ocasión del año jubilar y de los últimos documentos de la Iglesia en relación con éstas, se hace ver la importancia de las peregrinaciones en la piedad popular. Se elabora una interpretación teológica de 
estas manifestaciones, las cuales se presentan como un símbolo viviente del Pueblo de Dios peregrino, con su consiguiente dimensión eclesiológica y misionera; constatando, además, una revalorización de la peregrinación, tanto a nivel práctico como teórico. El peregrino, como figura de la religión en movimiento, muestra aspectos diferentes en comparación con los del practicante regular. Se trata de dos regímenes en los que se vive, de modo distinto, el tiempo y el espacio religioso.

El Prof. Galli expone la hermenéutica teológica de las peregrinaciones partiendo de la comprensión de Cristo como peregrino, enviado del Padre a mostrar el camino de salvación. La vida de Jesús puede ser interpretada como un peregrinaje. La liturgia llama a Jesús "Huésped y peregrino en medio de nosotros". Junto a la dimensión cristológica, la hermenéutica eclesiológica de la peregrinación es ineludible. El concepto de Iglesia peregrina, como pueblo de Dios inserto en el transcurrir histórico de los pueblos, ha sido muy fructífero en América Latina para relacionar la noción de pueblo de Dios con la realidad de la piedad popular, expresada en forma de peregrinaje, con sus dimensiones de penitencia, fiesta y comunionalidad.

La peregrinación es, además, inseparable de la esperanza. La esperanza es la virtud del peregrino, sabe que, en último término, está peregrinando hacia Dios. Espera contra toda esperanza. Vale esto especialmente para el peregrino evangelizador. "La Iglesia peregrina es, por su naturaleza, misionera, porque toma su origen de la misión del Hijo y del Espíritu Santo, según el propósito de Dios Padre". Así se afirma en Ad Gentes; es, entonces, posible decir que la Iglesia peregrina es el pueblo de Dios evangelizando.

Esta tarea evangelizadora conlleva presencia de la Iglesia en el espacio público, lo que implica mirar, desde un ángulo diferente, el problema del espacio eclesial. Este tema es tratado por la Prof. Sol Serrano al abordar la relación entre espacio público y espacio religioso, desde la perspectiva de la historia política en el Chile del siglo XIX, cuando el Estado transforma el modo como la religión se inserta en el espacio público. Se trata de la presencia de la Iglesia en dicho espacio, por medio de diferentes formas asociativas, tales como las cofradías -que vienen de la Colonia-, las nuevas asociaciones piadosas y las sociedades de beneficencia. Cada una con sus características propias.

Este modo asociativo permitió a la Iglesia hacer presente al espacio religioso en el espacio público, lo cual impidió la reclusión de la religión a la vida doméstica y a la conciencia individual. Contribuyeron las asociaciones a la regeneración social y la educación del pueblo, a través del disciplinamiento individual, la obediencia y el valor del autocontrol y del trabajo. Dan origen a un nuevo tipo de espiritualidad, caracterizado por una Reforma católica asimilada, que integra la Ilustración y, a la vez, participa de una fe colectiva, pública y emocional, propia del barroco, que ha incorporado el control, alejándose del exceso de exteriorización. Sucede, entonces, que la privatización del catolicismo barroco fue la publicidad del catolicismo moderno.

Lo interesante de este planteo es que muestra la complejidad que adquiere en el Chile decimonónico el fenómeno religioso. La autora no usa el término religiosidad popular para describir las formas religiosas que suelen considerarse como manifestaciones de este fenómeno. Se prefiere hablar de piedad religiosa, catolicismo barroco, piedad barroca, catolicismo tridentino, formas de devoción, piedad román- 
tica. Queda, así, implícita una discusión teórica acerca de qué se puede entender por religiosidad popular.

Esta problemática permite hacer un vínculo con el artículo del Prof. Rodrigo García, quien aborda el tema del espacio sagrado y la religiosidad popular desde perspectivas veterotestamentarias. Inicia la exposición con una delimitación de conceptos, siendo "religiosidad popular" el más desarrollado. Realiza un recorrido por las diferentes interpretaciones del fenómeno. Elige aquella que coloca el ejercicio del poder y las formas de control sobre las manifestaciones religiosas, como el elemento diferenciante entre lo popular y lo no popular. Esto le permite afirmar que el yahvismo verdadero fue inicialmente popular y solo en una época tardía se convirtió en oficial. Es muy sugerente la forma como se ilustran situaciones del Antiguo Testamento, a partir de los diversos modelos interpretativos de la religiosidad popular.

Esta metodología permite elegir el modelo más adecuado para entender la enorme complejidad del monoteísmo yahvista y el papel que tiene el Templo de Jerusalén en su desarrollo. Se muestra, también, la evolución que tiene el concepto de espacio sagrado, desde el Éxodo hasta el Exilio y la diferente comprensión que de este tienen los diversos grupos que constituyen el pueblo de Israel.

Si bien Yahvé no está ligado a ningún lugar sagrado, ya que desde el Éxodo la experiencia de la liberación precedió al culto en un lugar oficial y establecido, sin embargo, la fe necesita de la expresión religiosa espacial, de allí la gestación del Templo. En la fe judía se da también el proceso de interiorización y personalización del espacio sagrado, ya mencionado para las religiones no cristianas. El otro, su vida, su cuerpo, como espacio de libertad y objeto de respeto de su dignidad, es teofanía de Yahvé. La predicación profética y la coherencia con la experiencia del Éxodo serán siempre la prueba fundante de la autenticidad de la fe bíblica.

Con la referencia al artículo del Prof. García se finaliza el recorrido del contenido de este número de Teología y Vida. La secuencia de presentación de los artículos que aquí se ha hecho no es la que trae la revista. Ha sido un esfuerzo por construir una mínima estructura para un tema que siempre se presenta como variopinto, elusivo, y casi imposible de ser delimitado con un mínimo de consenso. Esta es la riqueza de la piedad popular que, como expresión de la fe del Pueblo de Dios sostenida por el Espíritu, crea permanentemente modalidades inéditas y busca nuevas formas de mediación para vivir y hacer accesible el Misterio del Amor que salva. 